\title{
Correction to: Intrathecal Baclofen Monotherapy and Polyanalgesia for Treating Chronic Pain in Patients with Severe Spasticity
}

\author{
Anuj Marathe ${ }^{1}$ (D) Sameer Allahabadi ${ }^{2}$. Alaa Abd-Elsayed ${ }^{3} \cdot$ Michael Saulino $^{4} \cdot$ Jonathan M. Hagedorn ${ }^{5}$. \\ Vwaire Orhurhu $^{6} \cdot$ Jay Karri $^{1}$
}

Published online: 26 February 2022

(c) The Author(s), under exclusive licence to Springer Science+Business Media, LLC, part of Springer Nature 2022

\section{Correction to: Current Pain and Headache Reports (2021) 25:1-18 https://doi.org/10.1007/s11916-021-00994-9}

The Abstract subheading "Summary" in the online version of the original publication contains an error. The original article has been corrected.

Publisher's Note Springer Nature remains neutral with regard to jurisdictional claims in published maps and institutional affiliations.

The original article can be found online at https://doi.org/10.1007/ s11916-021-00994-9.

Anuj Marathe

anuj.marathe@bcm.edu

1 Department of Physical Medicine and Rehabilitation, Baylor College of Medicine, Houston, TX, USA

2 TCU \&, UNTHSC School of Medicine, Fort Worth, TX, USA

3 Department of Anesthesia, Division of Pain Medicine, School of Medicine and Public Health, University of Wisconsin, Madison, WI, USA

4 Department of Rehabilitation Medicine, Moss Rehab and Sidney Kimmel Medical College at Thomas Jefferson University, Philadelphia, PA, USA

5 Department of Anesthesiology and Perioperative Medicine, Division of Pain Medicine, Mayo Clinic, Rochester, MN, USA

6 Department of Anesthesia, Division of Pain Medicine, University of Pittsburgh Medical Center, Susquehanna, PA, USA 